\title{
How Bad Is Unemployment in Tunisia? Assessing Labor Market Efficiency in a Developing Country
}

\section{Martin Rama}

Tunisia's unemployment rate has been among the highest in the world for almost two decades. This article claims that such a high rate reflects measurement problems rather than labor market inefficiency. After discussing the reasons why unemployment rates may not be comparable across countries and reviewing the tools that are available to analyze unemployment in a specific country, the article provides four pieces of evidence to substantiate its claim. Two of them relate to the criteria used in Tunisia to measure unemployment and the way these criteria have changed over time. Two use records on the number of active job seekers and vacancies as reported to the official employment agency. Together, this body of evidence suggests that unemployment has declined steadily over time and remains an issue for first-time job seekers only.

Tunisia's unemployment rate is unusually high. Drawing from the 1989 labor force survey, official estimates put that rate at 15.3 percent. Unofficial estimates for more recent years, based on labor force and employment forecasts, yield rates as high as 16 to 17 percent. Except for economies in transition to a market orientation, only a handful of countries-Algeria, Barbados, Finland, Jordan, the Seychelles, South Africa, Spain, and Trinidad and Tobago-report similar or higher rates (ILO, 1996). Whether unemployment is as high in Tunisia as the estimates suggest is an issue that the population census of 1994 could clarify, but it may take some time before the census data are processed, and it is not obvious that the computations will rely on an internationally comparable definition of unemployment. In the meantime, the country confronts major policy reforms, including the implementation of a free trade agreement with the European Union and the privatization and downsizing of state-owned enterprises. The problem is that the consequences of these reforms depend on how efficient the labor market actually is. 
If the available unemployment figures are correct, the labor market is very inefficient, which may well force the government to reconsider its policy choices. On the one hand, if it seems likely that those workers who lose their jobs as a consequence of trade liberalization and ownership divestiture will be unable to find new jobs in competitive sectors of the economy, or that they might manage to do so only after a long period of unemployment, the government presumably will hesitate to implement the reforms. On the other hand, the high unemployment rate could indicate significant distortions in the labor market that require a radical reform of labor market policies and institutions. In general, the almost automatic reaction to a high and stable unemployment rate is to aim at minimum wage and collective bargaining mechanisms that could be pricing workers out of jobs.

Assessing the efficiency of the labor market is seldom an easy task, even in industrial countries. Conceptually, the issue seems quite simple: the labor market is considered inefficient when a large number of individuals who would be willing to work (or to work more) at the prevailing wage rate are unable to do so. In practice, however, both work and willingness to work can be measured in different ways. For instance, it has been argued that Japan's unemployment rate, which is the lowest among industrial countries, is biased downward because some individuals who are not working are counted as employed, while they would be considered unemployed elsewhere (Hashimoto 1993). Similarly, Spain's unemployment rate, the highest in the industrial world, is said to be overestimated because many employed workers are not registered with the social security system (for conflicting views on the magnitude of this bias, see Franks 1994 and Blanchard and Jimeno 1995).

Measurement problems are magnified in the case of developing countries because self-employment and work within the family are much more prevalent than in industrial countries. As a result, the concept of willingness to work "at the prevailing wage rate" loses some of its meaning. For instance, for many women the distinction between working on a family farm (therefore, being a "worker") and taking care of the home (hence being "inactive") is tenuous, as is the distinction between being unemployed and working in the informal sector for many men. Similarly, it is unclear whether a young high school graduate looking for a job in the formal sector and meanwhile refusing to work in the informal sector should be considered unemployed or rather inactive. When all of these problems are taken into account, it becomes obvious the unemployment rate can be measured in more than one way (World Bank 1995c, chapter 3). It is therefore important to use the same measure when making comparisons across countries or over time for the same country.

The credibility of any assessment of labor market efficiency will vary substantially depending on the quality of the data available for the analysis. For example, microeconomic data on living standards may produce a detailed profile of the unemployed that could help explain why they are out of work. Data on earnings and individual characteristics of workers (such as education, experience, and the like) 
and their jobs can be used to evaluate whether different sectors pay the same wage to similar workers, which in turn could help identify the sources of labor market inefficiency. But in many cases these data are not available, and governments cannot postpone key policy choices until they are collected and processed. The challenge is therefore to assess labor market efficiency based on the kind of data usually published by the statistical offices of developing countries. In this respect, focusing on a country like Tunisia represents an even bigger challenge. Nowhere in the world is the paucity of labor market statistics more acute than in the Middle East and North Africa region (Rama 1997). If a credible assessment of labor market efficiency is feasible in Tunisia, then it should be feasible in other developing countries as well.

This article argues that Tunisia's labor market is not nearly as inefficient as the unemployment figures suggest. Four pieces of evidence substantiate this claim. Each of them is partial and subject to criticism, but they all point in the same direction. The first concerns the criteria used to measure the labor force, and the way these criteria have changed over time. The second relates to the methods used to forecast the size of the labor force and total employment since the last labor force survey. The third relies on the number of active job seekers and the number of available vacancies, as reported to the official employment agency. The last uses these records to compare the efficiency of the matching process between job seekers and vacancies in Tunisia with that of other countries.

The same conclusion cannot be generalized to other developing countries with reportedly high unemployment rates, however. The article highlights the problems surrounding unemployment figures in developing countries, and suggests possible ways to understand what these figures really mean. But it does not claim that the biases observed in Tunisia plague the official figures of other developing countries as well. It only shows that biases of this sort may exist and may lead to inappropriate policy recommendations. Because the nature of any measurement biases is likely to vary from country to country, it is important to make the most of the labor market data available in each country. The four pieces of evidence examined here illustrate this broader proposition.

\section{A Conceptual Framework}

One of the problems in deciding whether an unemployment rate is actually "high" or "low" occurs because the most popular model of the labor market sets the equilibrium unemployment rate at zero. In practice, however, even the tightest labor market displays a strictly positive unemployment rate. In the basic model, shown in figure 1, as wages rise (on the vertical axis), more people are willing to seek jobs. This is shown by the increase in the labor supply (on the horizontal axis) along the upward-sloping line. Conversely, when wages are extremely low, employers are willing 
to hire large numbers of workers. But as wages rise, labor demand declines along the downward-sloping line. At the wage level $W_{E}$ the number of jobs offered equals the number of workers seeking employment. Labor market equilibrium is thus characterized by no unemployment at all.

Within this simple model, the only reason why unemployment could be "high" (strictly speaking, positive) is because wages are misaligned. Assume that a minimum wage or a union-negotiated increase pushes the wage level up (in figure 1, from $W_{E}$ to $W_{A}$ ). In this case, $L S_{A}$ individuals would be willing to work, but only $L D_{A}$ would find jobs, because wages would be so high that employers could not afford to hire many workers. This distorted equilibrium is what comes to the minds of many economists when data reveal a high unemployment rate. But in developing countries, usually characterized by a large informal sector, this interpretation is problematic. Indeed, most of the potential sources of wage misalignment are irrelevant in the informal sector: minimum wages are not enforced and unions are almost nonexistent. The

Figure 1. A Basic Model of the Labor Market

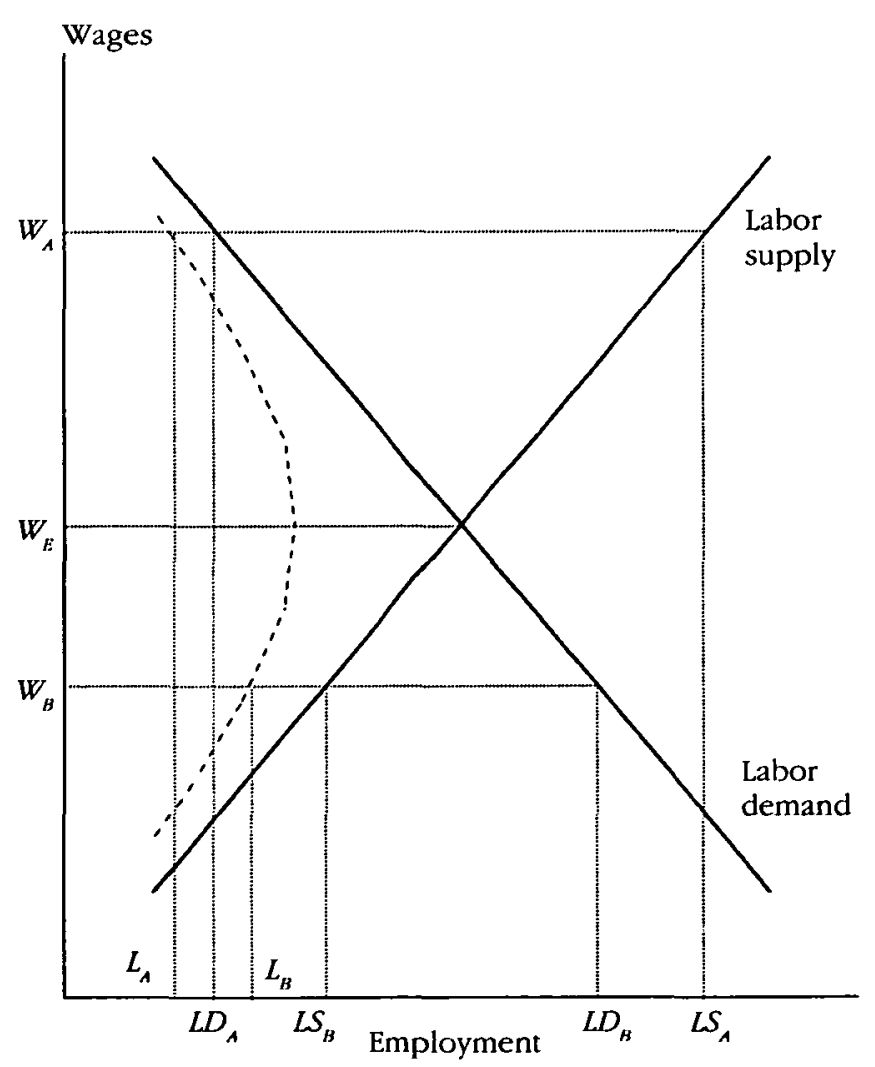

Source: Author's calculations. 
labor demand curve in figure 1 corresponds to the formal sector only. As wages in this sector rise, some workers lose their jobs. But instead of being forced into unemployment, they shift to the informal sector.

There are several ways of introducing equilibrium unemployment in simple models of the labor market like the one represented in figure 1 . One assumes that workers in the informal sector cannot join the formal sector without previously spending some time unemployed. In the context of development economics, this assumption has been justified on the grounds that the formal sector is mostly urban. Agricultural workers choose between staying in rural areas and migrating to urban centers, where they may either find a job in the modern sector or remain unemployed. The equilibrium unemployment rate is the one that equalizes the expected payoffs of these two alternatives (Harris and Todaro 1970). That the informal sector is quite large in urban areas makes this explanation of unemployment unconvincing, however. Rural migrants could indeed work in the urban informal sector while waiting for openings in the formal sector.

A second way of introducing unemployment consists of assuming frictions in the matching process between job seekers and vacancies. The labor market is actually characterized by large flows in and out of employment. There are always individuals who quit their jobs, are fired, retire, or die, while newcomers are constantly joining the labor force. It takes time for job seekers to learn about openings that are suitable to them and for firms to find candidates who meet their needs. So even if the supply of labor were equal to demand at the aggregate level, there would always be some individuals in search of a job and some firms in search of the appropriate workers (Pissarides 1985; Blanchard and Diamond 1989).

Because of the frictions in the matching process, actual employment is less than both labor supply and labor demand, as represented by the broken curve in figure 1 . For instance, when the wage level is high (equal to $W_{A}$ ), employment is given by $L_{A}$ and there are simultaneously $L D_{A}-L_{A}$ unfilled vacancies and $L S_{A}-L_{A}$ unsuccessful job seekers. Conversely, when the wage level is low (equal to $W_{B}$ ), the employment level is $L_{B}$ and there are simultaneously $L D_{B}-L_{B}$ unfilled vacancies and $L S_{B}-L_{B}$ unsuccessful job seekers. Although these two situations may look alike in terms of employment, they are radically different in terms of their ratios of vacancies to unemployment. Job seekers have better prospects of finding a job in the second situation, so the time during which they are unemployed should be shorter. More generally, the joint behavior of unemployment and vacancies can provide more information on the functioning of the labor market than the mere unemployment rate does.

A convenient representation of the joint behavior of unemployment and vacancies is provided by the Beveridge curve (figure 2). The curve on the left is based on the diagram in figure 1 . Point $A$ in this curve corresponds to the wage level $W_{A}$, while point $\mathrm{B}$ corresponds to the wage level $W_{B}$. The other curve displays a higher number of unsuccessful job seekers for any number of vacancies, or equivalently, a higher number of vacancies for any number of unemployed persons. These two curves are 
Figure 2. The Beveridge Curve

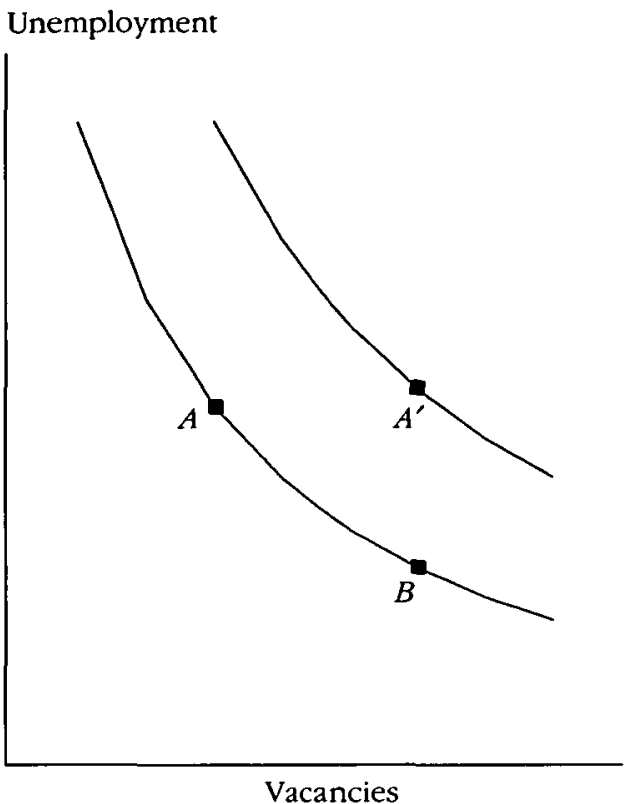

Source: Author's calculations

useful to illustrate the difference between movements along the Beveridge curve and shifts of the Beveridge curve. A movement from point A to B indicates that the labor market has tightened, without changing its overall efficiency. Business cycles are characterized by back-and-forth movements of this kind. A movement from point $A$ to point $A^{\prime}$, in turn, reflects a more inefficient labor market. That is, the same number of job seekers remain unemployed despite a larger number of unfilled vacancies. For instance, it has been argued that labor market policies and institutions in Europe are such that the temporary increase in unemployment created by the oil shocks (from $B$ to $A$ ) has reduced labor market efficiency and become a more permanent situation (from $A$ to $A^{\prime}$, rather than back to $B$ ).

Another convenient tool to assess the importance of labor market frictions is provided by matching functions. These functions link the number of new placements, $H$, to the number of job seekers, $U$, and the number of vacancies, $V$. In a wellfunctioning labor market, $H$ should increase when more individuals are actively searching for a job and when more vacant posts are available as well. In analytical terms, the number of placements is represented as follows:

$$
H=b(U, V)
$$

where $h($.$) is the matching function. The shape of this function has been investi-$ 
gated for several industrial countries. The econometric results show that, in general, if the number of job seekers and the number of offers doubled, placements would roughly double too. In technical terms, the $h($.) function is characterized by constant or near-to-constant returns to scale. The results also show that both arguments of the function matter. Even in cases of massive job destruction, as in the transition economies, the stock of the unemployed remains an important determinant of the flow of hirings (see Burda 1993, on the former East Germany). This is in sharp contrast with the frictionless labor market shown in figure 1. Indeed, in that model, when the wage level was $W_{A}$, employment was determined exclusively by labor demand.

The analysis in this article proceeds as follows. First the supply of labor in Tunisia is measured according to internationally comparable criteria. The criteria used in Tunisia make the labor supply curve in figure 1 appear to be much farther to the right of the diagram than in other countries. Moreover, these definitions have changed over time in a way that shifts the curve even farther to the right. Second, employment estimates for recent years are examined. The criteria used in Tunisia amount to representing the labor demand curve in figure 1 to the left of its actual location. Third, based on government placement agency records on the number of vacancies and job seekers, a rudimentary Beveridge curve is drawn. This exercise shows a movement in the direction of a tighter labor market in recent years, like the one from point $A$ to point $B$ in figure 2 . And finally, to assess whether the labor market operates efficiently, a matching function is estimated for Tunisia. Except for first-time job seekers, the results are similar to those observed in several industrial countries over periods characterized by moderate unemployment rates. These results, together with the other evidence, suggest that unemployment is not a serious problem in Tunisia except for first-time job seekers.

\section{Defining the Labor Force}

The criteria used to measure unemployment in Tunisia differ from those commonly applied in other countries in two respects. The most frequently mentioned discrepancy concerns job seekers of ages 15 to 17 , and 60 and above, who appear on the unemployment rolls in most countries but who are not included in Tunisia's unemployment figures. Because these people are available to work, observers believe that official unemployment figures underestimate the magnitude of the problem. The second discrepancy, however, more than offsets this underestimation. Tunisian data count a set of inactive people (mostly housewives) as unemployed, although they would not be counted as such elsewhere.

In 1966 the definition of the labor force used in Tunisia was similar to that used in other countries. The labor force thus included all individuals who either held a job or 
were actively searching for one. In the discussion here, this definition is referred to as the effective labor force. In Tunisia, however, this definition was considered problematic because it yielded a higher unemployment rate for men than for women, which is uncommon. Of course, this gender gap may say more about the condition of women at that time than about the appropriateness of the definition. But in practice, the problem led to several endeavors by the statistical office (Institut national de la statistique) to identify potentially discouraged job seekers among inactive women. For this reason the standard definition of the economically active population was gradually extended to include the marginal labor force first, and then the potential labor force.

The marginal labor force comprises individuals who do not consider themselves economically active but who did some work in the preceding three months. More specifically, all the interviewees were first asked whether they considered themselves employed, unemployed, housewives, students, in military service, and so on. Then, all the inactive respondents, apart from those in military service, were asked whether they had worked in the three months preceding the survey. Those who did were switched from inactive to marginally active, and then asked whether they worked at least one hour during the week preceding the survey. The answer was overwhelmingly negative, which is not surprising given that these individuals reported that they were inactive. As a result, most of the marginally active were counted as unemployed.

The potential labor force consists of a subset of housewives who have some free time and would like to have a job. More specifically, those interviewees who classified themselves as housewives and who did not do any other work during the previous three months, not even as family workers, were asked whether their housekeeping tasks kept them busy all day. If so, these women are considered inactive. But if not, they were asked whether they would be willing to take a job if it were offered. An affirmative answer shifts them from inactive to potentially active. Not surprisingly, most of them were reported unemployed when asked whether they worked at least one hour during the week preceding the survey.

A consistent presentation of labor force and employment data based on existing population censuses and labor force surveys is shown in table 1 . In this presentation all job seekers aged 15 to 17 or 60 and above are counted as unemployed, so the data are comparable to those of other countries. The presentation also uses the questionnaires of the censuses and surveys to disentangle whether the figures include the marginal and the potential labor force. The table should be interpreted with caution though, because it is based on published data and not on the original information. In particular, when the same presentation used to construct the table is applied to much narrower groups of individuals (for example, men aged 60 and above) certain inconsistencies emerge that highlight the limits of this approach. At an aggregate level, however, table 1 yields two insights.

The first insight is that unemployment has declined over time. This is not the story line that emerges from official unemployment figures, which, after adding young 
and old job seekers, have fluctuated around 15-16 percent from 1966 to 1989. (In 1980 the official unemployment rate was lower, but that year appears to be an outlier). If comparable unemployment rates are considered, instead of the official ones, the story is one of decreasing unemployment. For instance, if data on the effective labor force are used, the unemployment rate declines from 15.2 percent in 1966 to 12.1 percent in 1980 to 11.2 percent in 1989 . And the trend is similar when using broader definitions of the labor force. (Again, 1980 was the only exception, a year that may be seen as idiosyncratic).

The second insight is that most of the unemployment problem is associated with new entrants to the labor force. When measured according to standard criteria, the unemployment rate was around 11.2 percent in 1989. But when first-time job seek-

\begin{tabular}{lrrrrrr}
\hline Table 1. Unemployment Rates in Tunisia & & & & & \\
\hline Unemployment data & 1966 & 1975 & 1980 & 1984 & 1989 & 1990 \\
\hline Number of persons (thousands) & & & & & & \\
A. Employed, ages 15+ & 927.3 & $1,366.5$ & $1,576.9$ & $1,786.4$ & $1,978.8$ & - \\
B. Effective actives, ages 15+ & $1,093.7$ & - & $1,793.3$ & - & $2,229.1$ & - \\
C. Marginal actives, ages 15+ & - & - & 16.5 & - & 89.1 & - \\
D. Effective + marginal, ages $15+$ & - & $1,621.8$ & $1,809.8$ & - & $2,318.2$ & - \\
E. Potential actives, ages 15+ & - & - & - & - & 42.4 & - \\
F. Total actives, ages 15+ & - & - & - & $2,137.2$ & $2,360.6$ & - \\
G. First-time job seekers, & & & & & & \\
$\quad$ ages 18-59 & - & - & - & - & 135.2 & - \\
H. First-time job seekers, & & & & & & \\
$\quad$ ages 15-17 & - & - & - & - & 54.8 & - \\
I. First-time job seekers, & & & & & & \\
$\quad$ ages 15+ & 40.8 & 119.1 & 89.8 & - & 190.0 & - \\
Official unemployment rates (percent) & & & & & & \\
Total & 15.21 & 15.74 & 12.87 & 16.41 & 16.17 & - \\
Household heads & 11.74 & - & 7.23 & - & - & 1.40 \\
Comparable unemployment rates (percent) & & & & & & \\
(B - A)/B & 15.21 & - & 12.07 & - & 11.23 & - \\
(D - A)/D & - & 15.74 & 12.87 & - & 14.64 & - \\
(F - A)/F & - & - & - & 16.41 & 16.17 & - \\
Rates excluding first-time job seekers (percent) & & & & & \\
(B - A - I)/(B - I) & 11.92 & - & 7.43 & - & 2.95 & - \\
(D - A - I)/(D - I) & - & 9.06 & 8.32 & - & 7.02 & - \\
(F - A - I)/(F - I) & - & - & - & - & 8.84 & - \\
\hline
\end{tabular}

- Not available.

Source. Recensement général de la population et des logements, 1966, Recensement général de la population et des logements, 1975; Enquête population-emploi, 1980, Recensement général de la population et de l'habitat, 1984; Enquête nationale population-emploi, 1989, Enquête nationale sur le budget et la consommation des ménages, 1990 (tables produced for the World Bank); Institut national de la statistique, Tunis. 
ers are excluded, the "core" rate was less than 3 percent. Moreover, the unemployment rate of heads of households was as low as 1.4 percent in 1990. Although these figures refer to a subset of the unemployed, they are more informative about the efficiency of the labor market than the consolidated unemployment rates. Many first-time job seekers can be considered "voluntarily" unemployed because they take advantage of family support to wait for the right job opening, while rejecting existing work opportunities that are attractive. Voluntary unemployment is less likely among those who had a job and lost it.

\section{Methods of Forecasting Unemployment}

Estimates of the unemployment rate for years after 1989 are based on a comparison of employment forecasts and labor force projections. The problem here is that the method used to forecast employment leads to a downward bias, while the method used to forecast the labor force leads to an upward bias. By underestimating the number of people at work and overestimating the number of people available for work, these two biases lead to an unrealistically high unemployment rate.

The employment forecasts are produced by the planning ministry (Ministere $d u$ développement économique), which updates the 1989 employment figures to account for the creation of new jobs and the destruction of old ones. New jobs are identified from employers' reports to the investment promotion agency (Agence de promotion des investissements). Job destruction is estimated based on social security records and on data from the labor inspection of the ministry of labor. Based on this approach, 2.13 million people would have been at work in Tunisia in 1993, a figure used here to illustrate the bias resulting from current forecasts. But this approach has two shortcomings: the estimates of job creation and job destruction refer only to the formal sector; and they probably underestimate job creation more sharply than job destruction.

One reason why job creation is underestimated is that the declaration of new jobs by employers is not compulsory. In the past, employers had to report their investment projects and the associated new jobs to the Agence de promotion des investissements in order to get subsidies; but reporting is now a mere formality. Moreover, employers are only asked to declare new permanent jobs, whereas employment growth in recent years has tended to rely heavily on temporary contracts, even in the formal sector. Last but not least, there is an evasion problem. Firms tend to declare only the personnel they register with the social security system. And they do not register all their personnel because they prefer to escape payment of social security contributions.

The coverage of job destruction, which is based on social security records and data from the labor inspection of the ministry of labor, is better than the coverage of job creation. It still refers only to the formal sector but covers both permanent and tem- 
porary workers. As a result of these differences, the planning ministry underestimates employment growth in the formal sector. Moreover, the methodology used by the ministry implicitly assumes zero employment growth in the informal sector of the economy, although most observers agree that this sector has expanded since 1989. The underestimation of employment growth in both the formal and (to a much larger extent) the informal sectors suggests that employment forecasts are likely to suffer from a substantial downward bias.

Forecasts of the labor force, in turn, extrapolate from the growth rate observed in previous years. Taken at face value, the data from population censuses and labor force surveys imply the Tunisian labor force grew at a rate of roughly 3 percent a year between 1980 and 1989. Part of this growth is fictitious, however, because it results from the change in the definition of the labor force. As noted earlier, the 1989 survey included the potential labor force among the economically active, but the 1980 labor force did not. A more reliable estimate can be obtained by comparing the effective labor force in both years, which yields an annual growth rate close to 2.5 percent. The comparison between the total labor force (including marginal and potential actives) in 1984 and 1989 yields an even lower annual growth rate of about 2 percent.

A different picture of unemployment emerges depending on which of these three growth rates is used. If the 3 percent annual growth rate of the labor force is applied to the 1989 effective labor force, the corresponding figure in 1993 would have been 2.51 million. When the 2.5 percent growth rate is used instead, the effective labor force forecast is 2.46 million. At a 2 percent growth rate, it is 2.41 million. Assume for a moment that the planning ministry's employment forecast is not biased, so that total employment in 1993 can be estimated at around 2.13 million. Depending on whether the labor force actually grew at a rate of $3,2.5$, or 2 percent a year, the unemployment rate in 1993 would thus be $15.1,13.1$, or 11.7 , respectively. Note that this last figure is close to the one observed in 1989, which suggests some stability of the unemployment rate in recent years. But in fact total employment is underestimated, so that the "true" unemployment rate for 1993 was likely to have been lower.

\section{Unemployment versus Vacancies}

The efficiency of the Tunisian labor market can also be assessed based on trends in the number of unfilled vacancies as well as in unemployment. For this measurement, the data collected by the government's placement agency (Agence Tunisienne pour l'Emploi, or ATE for short) turns out to be particularly valuable. When Tunisia was a control economy, publicly owned firms had to report all of their vacancies to the ATE, which was in charge of filling them based on its own records of job seekers. As the economy became more market oriented, the obligation of reporting vacancies to the ATE remained, but the share of hirings directly processed by firms increased. 


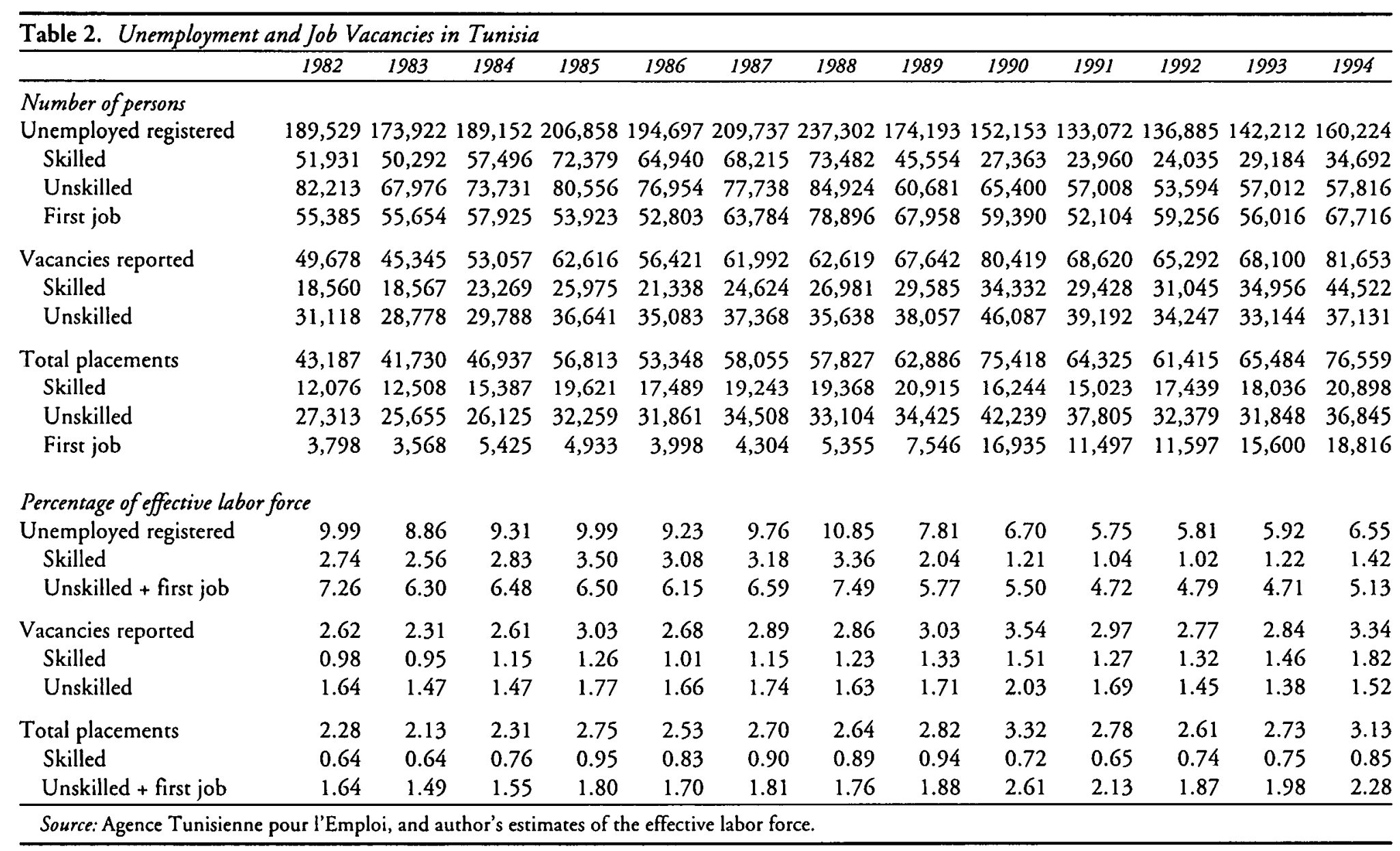


Despite the shift from a control to a market economy, however, the ATE still is an important labor market intermediary.

The absolute numbers of job seekers registered with, and vacancies reported to, the ATE from 1982 through 1994 is shown in table 2. The table also presents the data on job seekers and vacancies in percentage of the effective labor force, with the latter estimated based on comparable observations from population censuses and labor force surveys under the assumption of a constant growth rate between observations. The relative stability in the number of placements by the ATE is striking. If anything, the ratio between these placements and the effective labor force has gone up over time. At the beginning of the period considered, total annual placements amounted to slightly more than 2 percent of the effective labor force; at the end of the period the figure was close to 3 percent. These figures suggest that ATE records may still reflect the main trends in unemployment and vacancies, despite the shift to a market economy.

The picture that emerges from these records is one of an increasingly tight labor market. This interpretation is straightforward when the data are displayed in a Beveridge curve format, as in figure 3. Both unemployment and vacancies are measured in this figure as percentages of the effective labor force, which controls for the increasing size of the labor market. The clusters of points show that there were more vacancies and fewer job seekers in the early 1990 s than in the 1980 s. The similarity between the two groups highlighted in figure 3 and points A and B in figure 2 is striking and suggests that Tunisia experienced a movement along the Beveridge curve in recent years, in the direction of a tighter labor market. Given the intermediate position occupied by 1989 , the year of the most recent labor force survey, it is safe to conclude that the unemployment rate must be lower now than it was at that time.

The movement along the Beveridge curve is even more pronounced when only skilled workers and vacancies are considered. At the other end of the spectrum, firsttime job seekers may face higher unemployment rates despite an increase in the overall number of vacancies available. Several explanations for this trend are possible. The first is that sustained growth has created increased affluence. Families can now afford to support their young members for longer periods of unemployment, thus allowing them to find better jobs. Another possible explanation is that increased education raises the expectations of these new entrants to the labor market, making them reluctant to take the jobs that are actually available. Evaluating the empirical relevance of these two hypotheses is beyond the reach of this article, however.

\section{Placements and the Matching Process}

New jobs are created when employers find job seekers who are suitable to fill their vacancies and who are in turn interested by those vacancies. Limited job creation can 
Figure 3. Unemployment and Vacancies in Tunisia as a Percentage of the Labor Force

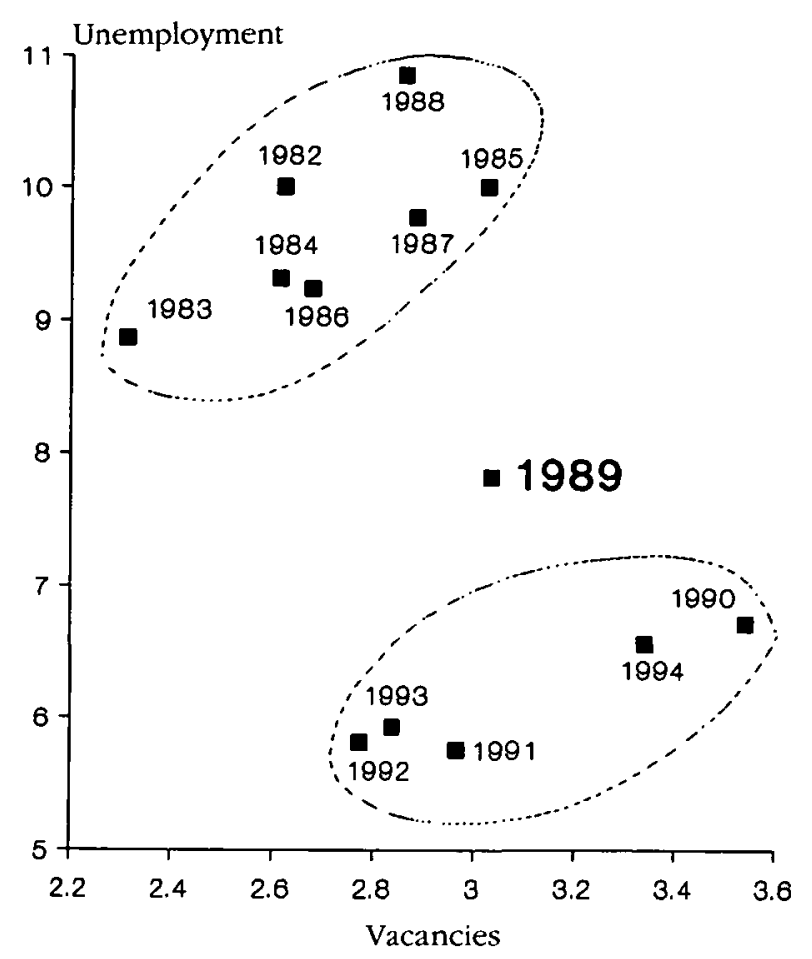

Source: See table 2.

therefore be expected when few vacancies are available or when the process of matching vacancies and job seekers is very inefficient. The Beveridge curve analysis in the previous section suggests that there is no shortage of vacancies in Tunisia. According to the ATE records, many more vacancies were reported in the early 1990s than in the 1980 s, even though firms are no longer obliged to report vacancies to the ATE. Therefore, if the unemployment problem were as serious as the official unemployment rates indicate, the matching process would be very inefficient in Tunisia. To assess whether this is so, matching functions estimated from ATE records can be compared to matching functions estimated in industrial countries during periods of moderate unemployment.

Whereas the ATE records distinguish between skilled and unskilled vacancies, they consider a third category of unemployed workers, namely first-time job seekers (who are not considered skilled by employers). Therefore, two separate matching functions are estimated. One explains new placements of skilled workers as a function of the number of skilled vacancies and of skilled job seekers. The other matching func- 
tion explains new placements of unskilled workers as a function of the number of unskilled vacancies and of unskilled and first-time job seekers.

Matching functions are usually estimated under the assumption that a 1 percent increase in the number of vacancies leads to the same percentage change in the number of new placements, regardless of the number of job seekers. Conversely, a 1 percent increase in the number of job seekers is expected to lead to the same percentage change in the number of new placements, regardless of the number of vacancies available. In more technical terms, a Cobb-Douglas specification is used. Also, a time trend is often included in the specification. If, other things equal, the number of new placements increases over time, then it is safe to conclude that the matching process is becoming more efficient.

More specifically, matching functions usually take the form:

$$
\log H_{i t}=a_{i}+\alpha \log U_{i t}+\beta \log V_{i t}+\delta t+\varepsilon_{i t}
$$

where the subindex $t$ corresponds to the period, and the subindex $i$ to the district or geographic area to which the data refer. Depending on the countries, the $t$ or the $i$ dimension may be missing. Parameter $\alpha$ measures the percentage change in placements when the number of job seekers increases by 1 percent, and parameter $\beta$ the corresponding change when the number of vacancies increases by 1 percent. The sum $\alpha+\beta$ indicates the returns to scale of the matching function. If this sum is close to one, doubling the number of vacancies and job seekers roughly doubles the number of new placements. Parameter $\delta$, in turn, shows whether the efficiency of the matching process increases (for $\delta$ positive) or decreases ( $\delta$ negative) over time. Finally, $\varepsilon$ is an error term.

The results obtained when estimating matching functions on Tunisian data are reported in table 3 . Note that the results probably represent a lower bound for labor

\begin{tabular}{|c|c|c|c|c|c|c|c|}
\hline Sample & Data & Constant & $\begin{array}{l}\text { Time } \\
\text { trend }\end{array}$ & $\begin{array}{c}\text { Unem- } \\
\text { ployment }\end{array}$ & Vacancies & $\begin{array}{l}\text { Returns } \\
\text { to scale }\end{array}$ & $\begin{array}{c}\text { Adjusted } \\
\mathrm{R}^{2}\end{array}$ \\
\hline $\begin{array}{l}\text { Skilled job } \\
\text { seekers and } \\
\text { vacancies }\end{array}$ & $\begin{array}{c}\text { Yearly } \\
\text { data, } \\
\text { 1970-94 }\end{array}$ & $\begin{array}{c}0.684 \\
(0.525)\end{array}$ & $\begin{array}{c}0.0040 \\
(0.832)\end{array}$ & $\begin{array}{c}0.213 \\
(3.785)\end{array}$ & $\begin{array}{c}0.655 \\
(5.866)\end{array}$ & 0.87 & 0.850 \\
\hline $\begin{array}{c}\text { Unskilled job } \\
\text { seekers and } \\
\text { vacancies }\end{array}$ & $\begin{array}{c}\text { Yearly } \\
\text { data, } \\
\text { 1970-94 }\end{array}$ & $\begin{array}{c}0.271 \\
(0.220)\end{array}$ & $\begin{array}{c}0.0261 \\
(2.899)\end{array}$ & $\begin{array}{c}0.014 \\
(0.159)\end{array}$ & $\begin{array}{c}0.930 \\
(9.669)\end{array}$ & 0.94 & 0.912 \\
\hline
\end{tabular}

Source: Author's estimates, using data from the Agence Tunisienne pour l'Emploi. The dependent variable is the log of the yearly number of placements. Independent variables are the $\log$ of registered unemployed and the log of reported vacancies. Coefficients were estimated using the AR(1) method. These coefficients are statistically significant when the corresponding $t$-statistics (in parentheses) are higher than 2. The DurbinWatson statistics were 2.03 for the first equation and 2.06 for the second one, which implies that there are no auto-correlation problems. 
market efficiency. The data are from a government placement agency, and it would not be surprising if paperwork, red tape, and relatively low levels of effort by civil servants slowed down the placement process. Private sector matchmaking, operating through personal networks, press ads, and other informal mechanisms, is likely to be more efficient than matchmaking by the ATE. This distinction may not be that crucial when comparing the matching function in Tunisia and in industrial countries, given that the data used to estimate the latter are from public placement agencies like the ATE. Available estimates for industrial countries are reported in table A-1.

The estimates for Tunisia show a striking difference between a relatively efficient matching process for skilled workers, and a clearly inefficient one for unskilled and first-time job seekers. For the skilled segment of the labor market, these estimates are comparable to those in industrial countries. To some extent, this should not be surprising, given that a skilled job in Tunisia may be similar to an average job in an industrial country. Still, it is worth noting that the coefficients for Tunisia are almost indistinguishable from those for England and Wales, Sweden, or the United States in periods where the unemployment rate of these countries was well below 10 percent. In all of these cases, a 1 percent increase in the number of vacancies leads to larger variation in the number of placements than a 1 percent increase in the number of job seekers. In terms of the equation above, $\beta$ is larger than $\alpha$. Also, returns to scale (the sum $\alpha+\beta$ are close to one, or slightly below. But while the efficiency of the matching process declines over time in all of the industrial countries for which there are estimates (that is, parameter $\delta$ is negative), there is no such downward trend in the Tunisian data.

The picture is different when it comes to unskilled workers and first-time job seekers. The coefficients of the matching function in this case are not comparable to those observed in industrial countries. In particular, hirings appear to be driven by the stock of vacancies only, without any noticeable effect on the stock of job seekers. Note that this result aggregates over both first-time job seekers and unskilled unemployed, so that the role played by each of these two groups cannot be disentangled. But the lack of significance of the stock of job seekers could actually indicate that people in any or both of these two groups are not willing to take any job they are offered. This is most likely to be true in the case of first-time job seekers.

\section{Conclusion}

Tunisia's unemployment problem appears to have been greatly overstated. The use of comparable labor force definitions shows that unemployment has declined quite steadily over the years, which is hardly surprising given the remarkable performance of the Tunisian economy. The extent of the decline is partly hidden by the increase in the number of individuals seeking their first job. But the unemployment rate 
excluding first-time job seekers is low by any standard, and the unemployment rate of household heads is low too. Trends in the number of vacancies relative to the number of job seekers indicate that, if anything, the unemployment rate has declined since the last available estimation. A critical evaluation of the methods used to forecast unemployment rates and an econometric analysis of the data on vacancies and unemployment also suggest a relatively efficient labor market.

Although the diagnosis in this paper is based on piecemeal evidence, the 1994 population census offers a valuable opportunity to refine it. Data from this census should be processed using the standard international definition of unemployment, in addition to the one used in Tunisia, to allow more accurate comparisons with other countries. Processing the available information on first-time job seekers would improve our understanding of the reasons for their long unemployment spells, and help in designing employment policies targeted at this specific group.

Trade liberalization and public ownership divestiture will of course entail a significant reallocation of labor across firms and activities. But it is not obvious that these reforms will lead to a surge of unemployment in the short run because firsttime job seekers, who constitute the bulk of the unemployed, will be largely unaffected. The unemployment spells of first-time job seekers are usually determined by mismatch between skills and jobs, by expectations about public sector job openings, by the availability of family support during the job search, and the like. The decline and eventual increase in blue-collar jobs resulting from trade liberalization and privatization is probably irrelevant in this respect. Therefore, the level of unemployment rates in Tunisia does not justify delaying much needed structural reforms.

From a broader perspective, this paper highlights some caveats that may be useful when interpreting unemployment data in developing countries, as well as some shortcuts that may help assess labor market efficiency based on these data. If piecemeal evidence can be put together in a coherent way in a country such as Tunisia, where labor market statistics are partial and scattered, it should also be feasible in other developing regions of the world, where data tend to be better on average. This kind of critical evaluation of the available statistics is particularly recommended before undertaking labor market reforms, such as changing the wage-setting mechanisms or implementing safety nets. In this respect, no analytical model of the labor market can replace a good understanding of the facts. 


\begin{tabular}{|c|c|c|c|c|c|c|c|}
\hline $\begin{array}{l}\text { Sample } \\
\text { and source }\end{array}$ & Data & Constant & $\begin{array}{l}\text { Time } \\
\text { trend }\end{array}$ & $\begin{array}{c}\text { Unem- } \\
\text { ployment }\end{array}$ & Vacancies & $\begin{array}{l}\text { Returns } \\
\text { to scale }\end{array}$ & $\begin{array}{l}\text { Adjusted } \\
\mathrm{R}^{2}\end{array}$ \\
\hline $\begin{array}{l}\text { Austria } \\
\qquad \text { (Christl 1992) }\end{array}$ & $\begin{array}{c}\text { Monthly } \\
\text { data, } \\
1974-89\end{array}$ & $\begin{array}{l}-1.30 \\
(2.5)\end{array}$ & $\begin{array}{l}-0.0172 \\
(6.8)\end{array}$ & $\begin{array}{r}0.76 \\
(13.2)\end{array}$ & $\begin{array}{r}0.41 \\
(4.4)\end{array}$ & 1.17 & 0.66 \\
\hline $\begin{array}{l}\text { Former Federal } \\
\text { Republic of } \\
\text { Germany } \\
\text { (Burda 1993) }\end{array}$ & $\begin{array}{c}\text { Daily data, } \\
\text { by district, } \\
1990-92\end{array}$ & & & $\begin{array}{r}0.88 \\
(42.7)\end{array}$ & $\begin{array}{l}0.11 \\
(9.2)\end{array}$ & 0.99 & 0.93 \\
\hline $\begin{array}{l}\text { England and } \\
\text { Wales (Coles } \\
\text { and Smith } \\
\text { 1996) }\end{array}$ & $\begin{array}{c}\text { Data } \\
\text { by district, } \\
\text { for } 1987\end{array}$ & $\begin{array}{l}-1.19 \\
(-7.2)\end{array}$ & & $\begin{array}{r}0.34 \\
(10.6)\end{array}$ & $\begin{array}{r}0.66 \\
(16.0)\end{array}$ & 1.00 & 0.91 \\
\hline $\begin{array}{l}\text { Israel } \\
\quad \text { (Berman } \\
\text { 1997) }\end{array}$ & $\begin{array}{c}\text { Monthly } \\
\text { data, } \\
1978-90\end{array}$ & $\begin{array}{l}-1.00 \\
(-0.7)\end{array}$ & $\begin{array}{l}-0.0063 \\
(3.4)\end{array}$ & $\begin{array}{r}0.45 \\
(4.9)\end{array}$ & $\begin{array}{r}0.49 \\
(5.5)\end{array}$ & 0.94 & 0.63 \\
\hline $\begin{array}{l}\text { Sweden } \\
\text { (Edin and } \\
\text { Holmlund } \\
\text { 1991) }\end{array}$ & $\begin{array}{l}\text { Monthly } \\
\text { data, } \\
1970-88\end{array}$ & $\begin{array}{l}\text { Not } \\
\text { reported }\end{array}$ & $\begin{array}{l}-0.0005 \\
(-4.91)\end{array}$ & $\begin{array}{c}0.23 \\
(6.76)\end{array}$ & $\begin{array}{c}0.56 \\
(23.52)\end{array}$ & 0.79 & 0.91 \\
\hline $\begin{array}{l}\text { United States } \\
\text { (Blanchard and } \\
\text { Diamond 1989) }\end{array}$ & $\begin{array}{l}\text { Monthly } \\
\text { data, } \\
1968-81\end{array}$ & $\begin{array}{c}0.52 \\
(7.50)\end{array}$ & $\begin{array}{l}-0.0015 \\
(-2.40)\end{array}$ & $\begin{array}{c}0.35 \\
(3.90)\end{array}$ & $\begin{array}{c}0.54 \\
(6.90)\end{array}$ & 0.89 & 0.47 \\
\hline
\end{tabular}

Note: The dependent variable is the log of placements, referrals, or flows out of unemployment. Independent variables are the log of the registered unemployed and the log of the reported vacancies. $t$-statistics are in parentheses. A blank indicates that the corresponding variable was not included in the econometric analysis.

\section{Notes}

Martin Rama is senior economist with the Development Research Group of the World Bank. He would like to thank Nasser Jharsalli and Ben Zarthi for helpful conversations.

1. Note that the paper does not aim at delivering a comprehensive study of the Tunisian labor market. An overall picture of the main trends in this market at different points in time is provided by Morrisson (1986) and Zouari-Bouattour (1994). Also, several papers have dealt with specific labor market issues in Tunisia, including the determinants of earnings at the individual level (Abdennadher, Karaa, and Plassard 1994), the links between poverty and employment status (World Bank 1995b), the nature of social security programs for workers (World Bank 1993), the importance of intrahousehold transfers (IREP 1994), and the links between wage increases and productivity gains (Azam 1995, World Bank 1995a). The interested reader can fruitfully refer to those studies.

\section{References}

The word "processed" describes informally reproduced works that may not be commonly available through library systems. 
Abdennadher, Chokri, Adel Karaa, and Jean-Michel Plassard. 1994. "Tester la dualité du marché du travail: l'exemple de la Tunisie." Revue d'Economie du Développement 2(June):39-63, June.

Azam, Jean-Paul. 1995. "Labor Market Institutions." CERDI, Centre d'Études et de Recherches sur le Développement International, Clermont-Ferrand. Processed.

Berman, Eli. 1997. "Help Wanted, Job Needed: Estimates of a Matching Function from Employment Service Data." Journal of Labor Economics 15(1, part 2, January):S251-92.

Blanchard, Olivier, and Peter Diamond. 1989. “The Beveridge Curve." Brookings Papers on Economic Activity 1:1-60.

Blanchard, Olivier, and Juan F. Jimeno. 1995. "Structural Unemployment: Spain versus Portugal." American Economic Review 85(2) (Papers and Proceedings): 212-18.

Burda, Michael. 1993. "Modeling Exits from Unemployment in Eastern Germany: A Matching Function Approach." CEPR Discussion Paper Series 800. Centre for Economic Policy Research, London, U.K. Processed.

Christl, Josef. 1992. The Unemployment/Vacancy Curve: Theoretical Foundation and Empirial Relevance. New York: Springer-Verlag.

Coles, Melvyn, and Eric Smith. 1996. "Cross-Section Estimation of the Matching Function: Evidence from England and Wales." Economica 63(252):589-97.

Edin, Per Anders, and Bertil Holmlund. 1991. "Unemployment, Vacancies, and Labour Market Programmes: Swedish Evidence." In Fiorella Padoa Schioppa, ed., Mismatch and Labour Mobility. Cambridge, U.K.: Cambridge University Press.

Franks, Jeffrey. 1994. "Explaining Unemployment in Spain: Structural Change, Cyclical Fluctuations, and Labor Market Rigidities." IMF Working Paper 94/102. International Monetary Fund, Washington, D.C. Processed.

Harris, John, and Michael Todaro. 1970. "Migration, Unemployment, and Development: A TwoSector Analysis." American Economic Review 60(1):126-43.

Hashimoto, Mansanori. 1993. “Aspects of Labor Market Adjustment in Japan.” Journal of Labor Economics 11(1):136-61.

ILo (International Labour Office). 1996. Yearbook of Labour Statistics. Geneva.

IREP (Institut de recherches et d'études sur la population). 1994. L'entraide familiale, cahier 11. Tunis: Ministère du développement économique.

Morrisson, Christian. 1986. "Evolution of the Tunisian Labor Market." DRD Discussion Paper 279. World Bank, Development Research Department. Washington, D.C. Processed.

Pissarides, Christopher. 1985. "Short-Run Equilibrium Dynamics of Unemployment, Vacancies, and Real Wages." American Economic Review 75:676-90.

Rama, Martin. 1997. “A Labor Market Cross-Country Database." World Bank, Development Research Department, Washington, D.C. Processed.

World Bank. 1993. "Republic of Tunisia: The Social Protection System." Middle East and North Africa Department, Washington, D.C. Processed.

- 1995a. "Toward the 21 st Century." Country Economic Memorandum of Tunisia. Middle East and North Africa Department, Washington, D.C. Processed.

_. 1995b. "Poverty Alleviation: Preserving Progress while Preparing for the Future." Poverty Assessment of Tunisia. Middle East and North Africa Department, Washington, D.C. Processed. 1995c. World Development Report 1995: Workers in an Integrating World. New York: Oxford University Press.

Zouari-Bouattour, Salma. 1994 “Evolution du marché du travail Tunisien, 1983-1993." Université de Sfax, Tunisia. Processed. 